\title{
Características da Personalidade de Pais Incestuosos por Meio do Rorschach, Conforme o Sistema Compreensivo
}

\author{
Characteristics of the Personality of Incestuous Fathers Through Rorschach Method \\ According to the Comprehensive System
}

\author{
Lilian Pasqualini-Casado ${ }^{*} a$, Lucilena Vagostello ${ }^{b}$, Anna Elisa de Villemor-Amaral ${ }^{a}$ \\ $\&$ Regina Gattas do Nascimento ${ }^{c}$ \\ ${ }^{a}$ Universidade São Francisco/Itatiba, ${ }^{b}$ Universidade São Judas/São Paulo \\ ${ }^{c}$ Pontifícia Universidade Católica de São Paulo
}

\begin{abstract}
Resumo
Adotando-se os critérios legais de estupro (artigo 213 do Código Penal Brasileiro) como delimitações para essa conduta ou sintoma interpessoal, a finalidade desse estudo foi a de investigar características da personalidade de indivíduos responsabilizados criminalmente por estupros incestuosos. Participaram do estudo três adultos do sexo masculino, com semelhantes condições sociais, demográficas e educacionais, presos em uma penitenciária do estado de São Paulo pelos estupros das filhas biológicas. Os dados foram coletados por meio de entrevista e do Método de Rorschach, no Sistema Compreensivo de Exner (2003). Para a análise dos resultados foram selecionadas as seguintes variáveis: defensividade, autopercepção, capacidade de autocontrole, relacionamentos e percepção interpessoal, afeto e processos cognitivos aplicados na adaptação à realidade social. Ainda que estupradores não se constituam como um grupo homogêneo e que não haja um padrão de características universais que os represente, os principais resultados permitiram constatar a insuficiência de recursos subjetivos aplicados à percepção de si mesmos e à percepção do outro, dados que foram convergentes com os comumente retratados na literatura sobre psicologia de agressores sexuais.

Palavras-chave: Técnicas projetivas; Método de Rorschach; traços de personalidade; agressões sexuais.
\end{abstract}

\begin{abstract}
Taking into consideration the legal criteria related to rape (Brazilian Penal Code) as guidelines for this kind of conduct or interpersonal symptom, the objective of this study was to investigate the personality characteristics of individuals criminally responsible for incestuous raping. Participants were three male inmates, with similar social, demographic and educational levels, imprisoned at a State correctional institution in São Paulo for raping their biological daughters. The data were gathered through interviews and Rorschach Method, as Exner's (2003) Comprehensive System. To the analysis of the results the following variables were selected: defensiveness, self-perception, capacity for self-control, relationships and interpersonal perception, affect, and cognitive processing applied to social reality adaptation. Even though rapists do not constitute a homogeneous group and there are no standard universal characteristics that represent them, the main results showed evidence of their limitation on subjective resources applied to self-perception and perception of the others. It was convergent with common data found in the literature regarding the psychology of sexual aggressors.

Keywords: Projective techniques; Rorschach Method; personality traits; sex offenses.
\end{abstract}

Na atualidade, termos operacionais como agressão sexual, abuso sexual, ataque sexual e estupro incluem ações nas quais ocorrem ameaças, intimidação, exploração de autoridade ou força com o objetivo de impor atos sexuais contra alguém e para propostas de gratificação pessoal, que poderão ou não ser predominantemente de natureza sexual (Shaw, 1998). Mas, no Código Penal Brasileiro (2002), estupro define-se no artigo 213 (Decreto-lei 2.848, de 7 de

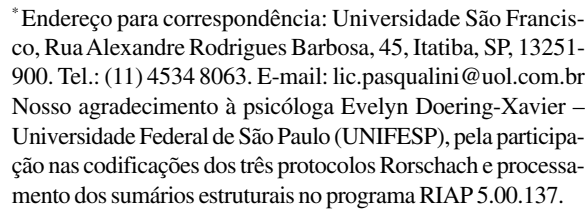

*Endereço para correspondência: Universidade São Francisco, Rua Alexandre Rodrigues Barbosa, 45, Itatiba, SP, 13251900. Tel.: (11) 4534 8063.E-mail: lic.pasqualini@uol.com.br Nosso agradecimento à psicóloga Evelyn Doering-Xavier Universidade Federal de São Paulo (UNIFESP), pela participação nas codificações dos três protocolos Rorschach e processamento dos sumários estruturais no programa RIAP 5.00.137.

dezembro de 1940, no Capítulo: Dos Crimes Contra os Costumes), como constranger mulher à conjunção carnal, mediante violência ou grave ameaça. É um crime específico quanto ao gênero dos envolvidos - o agente é exclusivamente o homem e a vítima exclusivamente a mulher portanto, o ato é sempre uma relação sexual (pênis/vagina) não consentida, admitido nas formas consumada ou tentada. Embora concomitante ao estupro sejam freqüentes outros atos libidinosos diversos da conjunção sexual que podem variar do toque até o coito anal - sob a ótica jurídica, estes são denominados atentado violento ao pudor e estão previstos no artigo 214 do Código Penal Brasileiro.

Há controvérsias quanto a se considerar o estupro um tipo de parafilia. Clínicos como Abel e Rouleau (1990) 
apóiam essa concepção porque encontraram nos relatos de estupradores um padrão característico dessa classificação diagnóstica que envolve fantasias recorrentes, controle falho sobre as condutas sexuais e sentimento de culpa até que o ímpeto para estuprar se reapresente. Outros autores, como Marshall e Barbaree (1990) colocam-se em desacordo com essa opinião e descrevem os estupradores como geralmente capazes de domínio sobre suas disposições sexuais delitivas, uma vez que reconhecem e respondem às regras de contenção social, ou ao menos o fazem, até que as possibilidades de serem pegos no ato sejam mínimas. Se as opiniões diagnósticas se dividem, as imagens amplamente difundidas nos diferentes segmentos sociais nem sempre se mostram procedentes dos fatos. Uma distorção típica no imaginário social é a de que estupros acontecem à noite, em lugares ermos, perpetrados por homens estranhos, portadores de doenças mentais.

Indubitavelmente, estupro é um comportamento complexo, multideterminado e o termo jurídico para uma conduta sexual delitiva que reverte em graves implicações para os protagonistas, familiares e sociedade. É também uma ocorrência médico-legal e uma distorção perigosa da sexualidade humana que até o momento não se configura como uma condição claramente descrita na linguagem nosográfica dos sistemas classificatórios e diagnósticos da psiquiatria: a CID-10 (Organização Mundial da Saúde [OMS], 1995) e o DSM-IV (American Psychiatric Association [APA], 2002; Fisher \& Beech, 2004; Groth \& Birnbaum, 1979; Herman, 1990; Knigth \& Prentky, 1990; Shaw, 1998).

As investigações científicas sobre o comportamento sexual agressivo inicialmente realçavam os elementos sexuais do ato, porém as limitações dessa abordagem foram notadas e os trabalhos redirecionados por uma ampla gama de perspectivas e modelos preferenciais. Uma abordagem que tem se mantido proeminente foi proposta por Marshall e Barbaree (1990), na qual consideram a infância e adolescência fases importantes tanto no desenvolvimento das disposições agressivas e sexuais como para aquisição de competências sociais. Esses autores ressaltam que uma socialização empobrecida e violenta interfere na conquista da autoconfiança e no acesso a interações sócio-sexuais apropriadas, predispondo ao uso da agressão. Neste contexto não seria nada surpreende indivíduos com auto-estima inadequada atribuírem distorções aos valores alheios, tornarem-se adultos mais sensíveis aos próprios interesses, desprovidos de modos para garantir o que querem ou solucionar seus impasses sem auto-imposição violenta, sendo justamente essas as disposições da personalidade e comportamentos que apontam com maior ênfase nos agressores sexuais.

Do ponto de vista psicodinâmico, Groth e Birnbaum (1979) abordam o estupro como sintoma de uma disfunção da personalidade que tanto poderia ser resultante do desenvolvimento insuficiente, como no outro extremo, ser uma reação transitória decorrente do estresse mobilizado sob circunstâncias extraordinárias. Embora reconheçam uma variedade de diferenças individuais, admitem que homens propensos ao estupro compartilham certas características genéricas como: aptidões cognitivas preservadas e senso crítico prejudicado sob pressão ou incitação emocional; percepções interpessoais deficitárias e restrição das habilidades empáticas; dificuldade para identificação e expressão adaptativa dos sentimentos e frustrações; identidade sexual ambígua ou pouco desenvolvida; baixa disponibilidade para introspecção e auto-observação.

Quanto às evidências clínicas de processos psicóticos ativos no momento dos crimes sexuais, estas são infreqüentes, no entanto, o diagnóstico de transtornos da personalidade anti-social, borderline, passivo-agressivo, esquizóide são descritos com relativa constância nos agressores sexuais identificados criminalmente, de modo similar ao que ocorre com uma parcela da população carcerária, (Gacono \& Meloy, 1994; Groth \& Birnbaum, 1979; Herman, 1990). Essas alterações da personalidade implicam em prejuízos nas relações e vínculos interpessoais; acentuado envolvimento com os próprios desejos e necessidades; falta de empatia; menores condições de controle; elevada disposição para o domínio e subjugo alheio. E, sob a óptica sócio-jurídica, a mais surpreendente característica dos agressores sexuais seria a ausência de condições clínicas ou orgânicas passíveis de invocar a diminuição da responsabilidade pela conduta criminal (Pimentel, Schritzmeyer \& Pandjiarjian, 1998).

No contexto familiar, as múltiplas formas de envolvimentos sexuais inadequados são descritas como relacionamentos incestuosos e reconhecidas como ocorrências graves que desestabilizam a família e predispõe a vítima a distúrbios psicológicos. Para que um ato sexual seja definido como incestuoso, três aspectos são relevantes: a natureza do ato; o grau do relacionamento e a idade dos envolvidos (Sholevar, 1978). Um entendimento errôneo sobre a natureza dessas relações seria tomá-las simplesmente como atos sexuais: o abuso da vítima na relação incestuosa é uma manifestação ou um sintoma de colapso na habilidade da família em regular as necessidades, os direitos e as funções dos seus diferentes membros, e a sexualidade é o meio de expressão da desorganização e disfunção familiar (Sholevar \& Schwoeri, 1998).

Willians e Finkelhor (1990) revisaram os trabalhos científicos publicados a partir da década de 80 endereçados às relações incestuosas entre pais e filhas com objetivo de avaliar as conclusões e implicações teóricas decorrentes. E os dados particularmente notáveis sobre pais incestuosos apontaram dificuldades empáticas e educacionais de modo amplo e consistente; negligência, isolamento e pouca habilidade social; baixa freqüência de abusos sexuais na infância, mas elevada frequiência de abusos físicos e de outras formas de maus tratos parentais, particularmente, a rejeição paterna e uma fraca evidência de identificação com papéis sexuais tradicionalmente masculinos. A partir das evidencias disponíveis sobre psicopatologia individual e disfunção familiar, Willians e Finkelhor (1990, p. 249) apóiam a presença de traços que os diferenciam de 
outros homens, mas advertem que "não há características universais ou algo que se aproxime disso . . . por enquanto não é possível esboçar um perfil único para pais incestuosos ..."

Testes de personalidade de auto-relato são usados na maioria dos estudos empíricos com agressores sexuais, particularmente o MMPI (Kalichman, 1991) e o MMPI-2 (Mann, Stenning \& Borman, 1992). Mais do que perfis patognomônicos desses indivíduos, seus resultados evidenciam como traços relativamente freqüentes a depressão, a ansiedade, a hostilidade, a baixa auto-estima, a impulsividade e múltiplos problemas interpessoais.

Quanto ao Rorschach, estudos realizados com agressores sexuais encarcerados não são numerosos e os mais consistentes, aplicando o Sistema Compreensivo, incluem os de Meloy, Gacono e Kenney (1994) com homicidas sexuais e o de Bridges, Wilson e Gacono (1998) com pedófilos. Os resultados trazidos por Bridges et al. (1998) compatibilizaram com modelos que propõem organização narcisista subjacente a alguns tipos de pedofilia, como também ao transtorno anti-social da personalidade e a psicopatia, uma vez que evidenciaram presença de baixa auto-estima ou excessivo autocentramento; negativismo e hostilidade; indiferença afetiva e pouca capacidade para a formação de vínculos; elementos depressivos e disfóricos; preocupações sexuais; concepções pessoais e interpessoais fantasiosas. Para os homicidas sexuais sobressaíram: raiva crônica e afetos negativos, pensamentos obsessivos decorrentes do não atendimento dos estados de necessidades, introspecção disfórica e desorganização do pensamento (Meloy et al., 1994).

Como se pode constatar, homens que estupram formam um grupo heterogêneo e é pouco provável que essa diversidade possa ser delineada em um único tipo de personalidade. Partindo dos critérios legais para as delimitações do comportamento ou sintoma interpessoal, o objetivo desse estudo foi o de investigar por meio do Método de Rorschach (Exner, 2003) algumas características da personalidade de genitores identificados e responsabilizados criminalmente pelos estupros das filhas. Considerando-se ainda a carência de estudos brasileiros com o Rorschach endereçados aos criminosos sexuais - particularmente aos que praticaram tais crimes no âmbito familiar - esse estudo pretende apresentar subsídios aos profissionais que atuam na área de avaliação psicológica e em programas de reabilitação específicos.

\section{Método}

\section{Participantes}

Tomaram parte nesse estudo três indivíduos presos pelo estupro das filhas. Os casos são procedentes de uma amostra ampla composta de estupradores reclusos em uma instituição penal no estado de São Paulo, específica ao que cometeram crimes contra os costumes, participantes da pesquisa de mestrado da primeira autora. A especificidade desses casos consistiu no fato dos genitores terem subme- tido no âmbito doméstico - mediante intimidação, força física e violência - suas primogênitas adolescentes a abusos e relações sexuais completas (estupro consumado).

O participante 1 nasceu em Minas Gerais, não freqüentou escola, estava com 44 anos de idade à época dos fatos e 29 meses de reclusão à época da pesquisa. O participante 2 nasceu no estado de São Paulo, não freqüentou escola, estava com 47 anos de idade à época dos fatos e 22 meses de reclusão à época da pesquisa. O participante 3 nasceu na Bahia, não freqüentou escola, estava com 44 anos de idade à época dos fatos e 22 meses de reclusão à época da pesquisa. De acordo com o que relataram nas entrevistas, a restrição de recursos financeiros foi o fator que lhes dificultou o acesso a educação formal, determinando o início das suas atividades laborativas ainda crianças, como lavradores. Além do enfrentamento dos períodos de restrição econômica, suas infâncias assinalaram rupturas nas unidades familiares que incluíram encaminhamento da prole a terceiros por abandono paterno e insuficiência de cuidados maternos (casos 1 e 3 ) ou por morte da genitora (caso 2), embora maus tratos físicos, abusos sexuais, ambiente doméstico violento, doenças mentais e antecedentes criminais nas famílias fossem negados; do mesmo modo que negaram no transcorrer do desenvolvimento ocorrências clínicas e/ou danos importantes, condutas anti-sociais, ideações e/ou tentativas de suicídio. Negaram interesse por experiências homossexuais e referiram elevada disposição para experiências heterossexuais, tanto pré como extraconjugais. Casaram-se muito jovens e mantiveram o status conjugal até a notificação policial dos fatos. O sustento econômico das famílias sempre se deu por meio de atividades lícitas autônomas ou relacionadas ao comércio. Descreveram-se como usuários de álcool não dependentes a partir da adolescência, mas consta nos autos que eram dados a embriaguez e quando embriagados tornavam-se mais violentos. A seguir se verá uma síntese descritiva dos episódios que resultaram nas suas condenações.

Caso 1. O participante obrigava a primogênita de 16 anos a despir-se - ou a despia à força - para verificar se era virgem e, sob tal alegação, introduzia o dedo na sua vagina. Este era um comportamento freqüente, como também as surras, as agressões verbais e a aplicação de castigos, como a retirada da escola e o confinamento da jovem sem causa aparente. No dia anterior ao estupro, agrediu-a fisicamente com violência e na tarde do dia seguinte, quando a jovem trabalhava sozinha na propriedade rural onde moravam, passou a ofendê-la moralmente e consumou o estupro. O episódio não resultou em gravidez.

Caso2. O participante estuprou a primogênita de 14 anos, mediante violência e ameaças, por 15 noites seguidas, o que resultou em gravidez. Durante toda gestação a intimidava para que não comentasse o ocorrido porque ambos seriam presos. Alguns meses após o nascimento dessa criança repetiu as investidas contra a filha, o que resultou no nascimento da segunda criança. As relações sexuais 
aconteciam numa propriedade rural, local onde a família residia e as práticas sexuais tiveram início quando da hospitalização da esposa.

Caso3. Na residência da família, geralmente de manhã, quando se encontravam a sós, usando faca, o participante ameaçava matar a primogênita de 17 anos se não mantivesse relações sexuais com ele e comentasse sobre tal fato, o que a fez esconder, inclusive do namorado, com quem se casou algum tempo depois. A jovem foi submetida em dias distintos a práticas sexuais, o que resultou na gravidez e no nascimento de uma criança.

\section{Instrumentos}

Os instrumentos utilizados foram: (a) entrevista semidirigida com finalidade de coletar dados históricos e (b) Método de Rorschach (Exner, 2003) para investigar as disposições da personalidade aplicadas aos processos de adaptação à realidade social. As informações complementares foram obtidas nas documentações disponíveis na instituição prisional.

Com base na literatura internacional sobre o tema e nos trabalhos conduzidos por Bridges et al. (1998), a análise do Rorschach considerou as seguintes hipóteses:

1. Defensividade na situação do teste.

2. Autopercepção distorcida.

3. Vulnerabilidade a pressões subjetivas e impulsividade.

4. Relacionamento e percepção interpessoal prejudicados.

5. Dificuldade de modular as expressões dos afetos. E, conforme Marshall e Barbaree (1990), considerou-se ainda as capacidades de auto-controle e de,

6. Adequação cognitiva a realidade social.

\section{Conjuntos das Variáveis Rorschach Analisadas}

1. Desempenho na situação do teste. $R$ (número total de respostas), $L$ (proporção de respostas de Forma, Lambda) e PER (comentários explicativos associados às respostas).

2. Autopercepção. EgoIndex (níveis do autocentramento ou da auto-estima); repostas de reflexo, $F R+r F$ (traços narcisistas); respostas Vista, $V$ (aspectos da autoimagem e disponibilidade para introspecção); conteúdos $M O R$ nas respostas (projeções de conotação negativa e de auto desvalia).

3. Níveis das pressões internas e condições de autocontrole. Respostas de sombreados difusos, Sum Y (interferência dos estados emocionais no psiquismo); respostas de movimentos inanimados, $m$ (interferência dos estados ideacionais no psiquismo); respostas de movimento animal, FM (nível das estimulações inter- nas decorrente do não atendimento de necessidades básicas); notas $D$ e AdjD (DAjustada)(vulnerabilidade a formas impulsivas de comportamentos).

4. Relacionamento e percepção interpessoal. Respostas de sensações táteis, SumT (desprendimento ou apego interpessoal); respostas de conteúdos alimentares, $F d$ (dependência emocional); relações entre figuras humanas completas, $H$ e figuras humanas parciais, $H d$ e pára-humanas, $(H) e(H d)$ (noção da identidade subjetiva e interesses interpessoais fantasiosos); respostas de movimentos humanos com qualidade formal negativa, $M$ - (déficits empáticos); predomínio de respostas de movimentos humanos passivos, $M p$, sobre os ativos, $M a$ (busca de gratificações fantasiosas em detrimento das reais); presença de Wsum6 nas respostas de conteúdos humanos (formas incoerentes do pensamento aplicados no âmbito relacional); respostas envolvendo perceptos ou atividades sexuais, $S x$ (extensão das preocupações sexuais) e a proporção $G H R$ (Good Human Representation):PHR (Poor Human Representation) (aspectos disfuncionais nas relações objetais).

5. Afeto. Quociente Afetivo, Afr (processamento dos estímulos emocionais); Índice de Intelectualização, $2 A B+A r t+A y$ (uso de racionalizações); respostas de espaço com qualidade formal negativa, $S \%$ - (raiva, oposicionismo e negativismo) e determinantes cromáticos e sombreados na mesma resposta, Col-ShdB (ambivalência emocional).

6. Ajustamento perceptivo e adequação cognitiva a realidade social. Respostas populares, $P$ (percepção das convenções sociais); respostas incomuns sem distorções perceptivas, $X u \%$ (percepções idiossincráticas); res-postas que transgridem a realidade, $X-\%$ (percepção distorcida das ações e intenções alheias); total de repostas de qualidades formal positiva, $X+\%$ e de Forma Pura com qualidade formal positiva, $F+\%$ (medidas gerais do ajustamento perceptivo à realidade).

\section{Procedimentos}

Os indivíduos concordaram em participar da pesquisa e assinaram o termo de consentimento livre e esclarecido. Após aplicação do Rorschach, os participantes foram entrevistados individualmente, ambos os procedimentos foram administrados pela autora principal, em 2002. Os protocolos foram classificados pela autora e discutidos com as co-autoras. Para o processamento dos sumários estruturais utilizou-se o programa RIAP versão 5.00.137. Os escores foram confrontados com os referenciais normativos de Nascimento (2002) para a cidade de São Paulo. 
Pasqualini-Casado, L., Vagostello, L., Villemor-Amaral, A. E. de \& Nascimento, R. G. do (2008).Características da Personalidade de Pais Incestuosos por Meio do Rorschach, Conforme o Sistema Compreensivo.

\section{Resultados e Discussão}

Tabela 1

Comparações dos Escores Rorschach dos Protocolos dos Pais Incestuosos e Normas Paulistanas

\begin{tabular}{|c|c|c|c|c|c|c|c|c|}
\hline \multirow{3}{*}{$\begin{array}{l}\text { Variáveis } \\
\text { Rorschach }\end{array}$} & \multicolumn{3}{|c|}{ Protocolos } & \multicolumn{5}{|c|}{ Nascimento (2002) } \\
\hline & \multirow[t]{2}{*}{ Caso 1} & \multirow[t]{2}{*}{ Caso 2} & \multirow[t]{2}{*}{ Caso 3} & \multicolumn{3}{|c|}{$(N=200)$} & \multicolumn{2}{|c|}{$R<19(N=104)$} \\
\hline & & & & $M$ & $D P$ & & $M$ & $D P$ \\
\hline \multicolumn{9}{|c|}{ 1. Desempenho } \\
\hline$R$ & 21 & 17 & 27 & 20.40 & 6.84 & 15.73 & 1.44 & \\
\hline$L$ & 1.33 & 1.13 & $2.86 \uparrow$ & 1.05 & 1.08 & 1.03 & 1.14 & \\
\hline$P E R$ & 0 & 1 & $5 \uparrow$ & 0.47 & 0.88 & 0.37 & 0.81 & \\
\hline \multicolumn{9}{|c|}{ 2. Autopercepção } \\
\hline$F r+r F$ & 0 & 0 & 0 & 0.52 & 0.89 & 0.47 & 0.71 & \\
\hline Sum V & 0 & 0 & 0 & 0.51 & 0.92 & 0.33 & 0.75 & \\
\hline$M O R$ & 0 & 1 & 0 & 0.77 & 1.24 & 0.60 & 1.00 & \\
\hline$F D$ & 0 & 0 & 0 & 0.67 & 1.01 & 0.73 & 0.98 & \\
\hline EgoIndex & $0.10 \downarrow$ & $0.06 \downarrow$ & 0.22 & 0.35 & 0.17 & 0.36 & 0.18 & \\
\hline \multicolumn{9}{|c|}{ 3. Níveis de Pressão Interna e Condições de Auto-controle } \\
\hline Sum $Y$ & 2 & 0 & 0 & 1.78 & 2.08 & 1.20 & 1.61 & \\
\hline$M$ & 0 & 0 & 0 & 1.39 & 1.39 & 1.16 & 1.20 & \\
\hline$F M$ & $1 \downarrow$ & 3 & 2 & 3.44 & 2.33 & 3.10 & 1.96 & \\
\hline$D A d j$ &.-1 &.-1 & 0 & -0.50 & 1.25 &.-0.51 & 1.03 & \\
\hline$D$ &.-1 &.-1 & 0 &.-1.07 & 1.57 &.-0.87 & 1.26 & \\
\hline \multicolumn{9}{|c|}{ 4. Percepção Interpessoal e Relacionamentos } \\
\hline Sum $T$ & $2 \uparrow$ & $1 \uparrow$ & 0 & 0.33 & 0.71 & 0.20 & 0.49 & \\
\hline$M$ & 1 & $0 \downarrow$ & 3 & 2.85 & 2.52 & 2.20 & 1.64 & \\
\hline$M-$ & 0 & 0 & 0 & 0.60 & 1.03 & 0.39 & 0.73 & \\
\hline Mativo & 0 & 0 & 0 & 1.41 & 1.59 & 1.14 & 1.16 & \\
\hline$H$ & 1 & $0 \downarrow$ & $4 \uparrow$ & 2.03 & 1.67 & 1.70 & 1.29 & \\
\hline$(H)$ & 0 & 0 & 0 & 0.94 & 1.09 & 0.78 & 0.84 & \\
\hline$H d$ & 2 & 0 & 3 & 1.38 & 1.74 & 0.85 & 1.14 & \\
\hline$(H d)$ & 0 & 0 & 0 & 0.50 & 0.88 & 0.36 & 0.62 & \\
\hline$F d$ & 0 & 0 & 0 & 0.26 & 0.54 & 0.18 & 0.45 & \\
\hline$S x$ & 1 & 0 & 0 & 0.32 & 0.82 & 0.19 & 0.62 & \\
\hline Wsum6 & 21 & 0 & 8 & 10.63 & 11.08 & 9.20 & 10.75 & \\
\hline \multicolumn{9}{|l|}{ 5. Afeto } \\
\hline$A f r$ & 0.62 & 0.70 & 0.59 & 0.56 & 0.26 & 0.57 & 0.26 & \\
\hline $2 A B+a r t+A y$ & 0 & 0 & 2 & 1.96 & 2.86 & 1.39 & 1.61 & \\
\hline$S-$ & 0 & 1 & 1 & 0.59 & 0.81 & 0.49 & 0.64 & \\
\hline$S$ & 1 & $3 \uparrow$ & 1 & 1.77 & 1.73 & 1.41 & 1.24 & \\
\hline Col-Shd Bl & 0 & 0 & 0 & 0.37 & 0.64 & 0.31 & 0.61 & \\
\hline WSum $C$ & 1.0 & 3.0 & 2.5 & 2.11 & 1.78 & 1.57 & 1.38 & \\
\hline$F C$ & 0 & 0 & 0 & 1.37 & 1.53 & 0.94 & 1.10 & \\
\hline$C F$ & $2 \uparrow$ & $2 \uparrow$ & 1 & 0.89 & 1.09 & 0.72 & 0.95 & \\
\hline$C$ & 0 & 0 & 1 & 0.36 & 0.74 & 0.25 & 0.55 & \\
\hline \multicolumn{9}{|c|}{ 6. Ajustamento Perceptivo e Adequação Cognitiva à Realidade } \\
\hline$X+\%$ & 0.43 & 0.35 & 0.30 & 0.44 & 0.12 & 0.46 & 0.13 & \\
\hline$F Q x+$ & 0 & 0 & 0 & 0.19 & 0.46 & 0.17 & 0.43 & \\
\hline$X u \%$ & 0.38 & $0.47 \uparrow$ & $0.48 \uparrow$ & 0.29 & 0.11 & 0.29 & 0.11 & \\
\hline$X-\%$ & 0.19 & 0.18 & 0.19 & 0.25 & 0.12 & 0.25 & 0.13 & \\
\hline$P$ & 4 & 3 & 5 & 4.08 & 1.79 & 3.69 & 1.59 & \\
\hline
\end{tabular}

Nota. $\uparrow=$ elevação do índice e $\downarrow=$ queda do índice. 


\section{Desempenho na Situação do Teste}

Os sumários estruturais evidenciaram protocolos válidos $(R>14)$ e $L$ alto apenas no caso 3 , sendo que os outros não se diferenciaram das expectativas normativas quanto aos desempenhos associativos e indícios de cautela situacional. No caso 3, a elevação dos indicadores $L$ e PER associada ao $R$ no limite normal superior, sugere que percepções restritas e que o enfrentamento das complexidades cotidianas através de orientações simplistas sejam tendências peculiares desse participante. Esses desvios normativos com menor significado de resistência situacional no protocolo 3 (L e PER elevados) e o atendimento normativo desses mesmos indicadores nos protocolos 1 e 2 já denotam tendências diferentes no modo dos participantes responderam as demandas do teste.

\section{Autopercepção}

No conjunto de variáveis aplicadas a autopercepção, as diferenças normativas ocorreram no EgoIndex dos protocolos 1 e 2, sendo a queda desses escores um indicativo de auto-estima cronicamente inadequada. A inadequação da auto-estima, em ambos os casos, não se mostrou relacionada a um senso de autolatria compensatória no modo como se comparam as demais pessoas $(F r+r F=0)$, a $o$ contrário, são menos autocentrados (EgoIndex $\downarrow$ ) e não investem suficiente atenção a si mesmos. Já o protocolo 3 não evidenciou alteração específica no EgoIndex, todavia, os L e PER simultaneamente elevados - descritos no módulo anterior - nessa dimensão da personalidade expressam percepções restritas da realidade externa e da realidade pessoal, e no âmbito interpessoal, uma marcada tendência à imposição da auto-imagem, liberada do auto-questionamento. Ainda que para o participante 3 as alterações na autopercepção não tenham se manifestado tão diretamente na elevação ou retração do EgoIndex, tornou evidente a inadequação da sua auto-imagem, o que apóia a hipótese de distinção estrutural entre esse e os outros casos. A importância desse achado permite admitir que as organizações das personalidades sejam heterogêneas, isto é, que existam diferenças psicológicas estruturais entre os participantes 1 e 2 (EgoIndex $\downarrow$ ) e o participante 3 (Estilo Lambda alto).

Outras duas ocorrências notáveis foram os níveis normativos de $V$ e $M O R$, não denotando repercussão emocional mais intensa ou vivências de sentimentos de inadequação, o que foi concordante com aspectos das auto-imagens trazidos nas entrevistas: "Estou satisfeito com a minha vida até agora... Só me faltou um pouco de estudo... Sou pobre, mas honesto... Até o delegado sentiu muito por saber que eu era uma pessoa boa...". As auto-imagens livres de nuanças pessimistas e equiparáveis aos demais, nos relatos e nos indicadores Rorschach, ao menos naquele período de reclusão, denotam: (a) menores condições para avaliação dos predicados pessoais e das condutas especificas no âmbito relacional (caso 1: EgoIndex $\downarrow$ e Hd >H; caso 2: EgoIndex $\downarrow$ e Htotal $=0$ e (b) carência de recursos para atribuir noções realistas e constantes a si mesmos e aos outros (nos três casos); o que será aprofundado no módulo Percepção Interpessoal. Além de não verbalizarem indícios de remorso ou vergonha, pelos parâmetros Rorschach, igualmente não evidenciaram disponibilidade à auto-inspeção $(F D=0$ e $\mathrm{V}=0)$, o que também pressupõe menores condições para ressignificar as imagens que formam de si.

Em síntese, não se verificou presença de traço narcísico $(F r+r F=0)$ como elemento nuclear exacerbando substancialmente o juízo valorativo e imagem que formam de si mesmos, o que reduz a possibilidade deste tipo de organização da personalidade estar associada as suas dificuldades de ajustamento social. Este dado igualmente se confirmou pela insuficiente mobilização de recursos associados à percepção das experiências $(L \uparrow)$, à auto-referencia (EgoIndex $\downarrow)$ e à auto-análise $(\mathrm{V}$ e $F D=0)$. Os resultados obtidos no módulo Autopercepção não atenderam tão restritamente os achados americanos que compararam agressores sexuais e não sexuais encarcerados. De acordo com o estudo Bridges et al. (1998), uma parcela dos pedófilos distinguiram-se pela presença de traços narcísicos em associação a prejuízos nas auto-imagens $(F r>0$; $M O R \uparrow)$ e a outra pelo sofrimento narcísico decorrente da situação carcerária $(F r>0, \operatorname{Sum} V \uparrow, M O R \uparrow)$, o que não são achados surpreendentes nos contextos prisionais, mas não verificados nos três casos estudados. Constatações similares foram feitas por Gacono e Meloy (1994) em amostras de psicopatas e homicidas sexuais quanto à presença de narcisismo patológico e sinais de conflito narcísico $(F r \uparrow e V \uparrow)$.

\section{Níveis das Pressões Internas e Condições de Autocontrole}

Embora sejam esperadas influências do ambiente carcerário no surgimento de vivências subjetivas de desconforto, refletidos mais freqüentemente na elevação dos indicadores Sum Y e m, os três participantes não denotaram tais presenças, sendo os seus níveis de mobilização emocional e ideativa equivalentes aos normativos. Entretanto, sobre a queda do indicador $F M$ no protocolo do participante 1 , optou-se pela interpretação que refere uma maior propensão a condutas autogratificantes ante pressões instintivas, e do mesmo modo para o participante 3 , em virtude do seu traço Lambda alto $(L \uparrow)$. Cabe ressaltar que estas ocorrências não significam impossibilidade de opção entre condutas que transgridam ou que atendam os referenciais socialmente estabelecidos, o que também se confirmou posteriormente na análise do módulo Ajustamento Perceptivo.

As notas $D$ e $A d j D$, que expressam as capacidades de controle atual e habitual também adequaram-se às normas, indicando que em condições gerais disponibilizam recursos para o enfrentamento das demandas cotidianas similares aos encontrados nos paulistanos não pacientes. Não deixando de considerar a participação que a intoxicação alcoólica possa desempenhar na liberação da agressividade e no cometimento dos crimes sexuais, nos três casos estudados o uso abusivo de etílicos, conforme descrito nas entrevistas e peças processuais, sugeriu ser evento mais típico aos estilos de vida do que específico aos delitos. 
Conforme o analisado até aqui, seus repertórios de condutas indevidas possivelmente se estabelecem mais associados à insuficiente representação/processamento internos e ao déficit de auto-crítica /auto-censura do que propriamente por vulnerabilidade à desorganização e à perda do auto-controle mediante estressores cotidianos, ou seja, por impulsividade do caráter ( $D, D A d j$ e $E A$ normativos; casos 1 e 2: es normativo; caso 3: es $\downarrow$ ).

\section{Percepção Interpessoal e Relacionamento}

A Sum T, que na dimensão interpessoal traduz o grau de proximidade física e emocional, apresentou-se elevada nos protocolos 1 e 2, não obstante, esta seja uma variável que poderá ser afetada, não tão de imediato, mas a médio prazo, por circunstâncias externas como, por exemplo, rupturas drásticas provocados por mudanças ou perdas nos relacionamentos afetivos. Como nos três casos constatou-se que fatores associados ao tipo dos crimes, a localização da unidade prisional e a restrição sócio-econômica das famílias corroboravam para que as visitas fossem raras ou mesmo inexistentes, é possível que o aumento das Sum T nos casos 1 e 2 esteja refletindo a intensidade emocional dessas experiências de privação do ambiente extra-muros. Mesmo que esse evento pareça não ter sido tão significativo no caso 3, em razão da ausência de $T$, a elevada medida de representação formal das figuras humanas $(H \uparrow ;$ WSum $6=$ 8; $M-=0$ ), ao menos em situações como a de reclusão, permite a suposição de que para esse participante a privação de contato social tenha resultado numa outra dinâmica psíquica, ou seja, na busca compensatória do outro via ideações fantasiosas e idiossincráticas $(M u>M o, 2: 1 ; M p$ $>M a, 3: 0)$. Ainda nesse mesmo protocolo as GHR superaram numericamente as $P H R(5: 2)$, o que atende as expectativas normativas, porém, do ponto de vista qualitativo as $G H R$ apresentaram indicativos de graves falhas na representação do outro e da própria identidade subjetiva (percepção humana na primeira resposta da PR III "um esqueleto" e a supressão de gênero nos demais representações humanas). No protocolo 1 , os conteúdos $H$ explicitaram representações mentais das figuras humanas predominantemente fragmentárias, fantasiosas $(M-=0, M p>M a)$, bem como preponderância das $P H R$ sobre as $G H R(2: 1)$, sendo ambos os eventos altamente correlacionados com protocolos de indivíduos cujas vidas relacionais distinguem-se por conflitos ou fracassos e interesse parcial pelos demais.

As freqüências de $A G$ em $M$ foram normativas nos protocolos 1 e 3 , o que de certo modo não se esperaria nos criminosos sexuais. Assim pensou-se que tais ausências não se explicam como fraca disposição para interagirem com agressividade mas, possivelmente, como uma fraca representação mental das atitudes hostis nas interações sociais, portanto, um maior potencial para tais atuações, já que não percebem suas ações como agressivas e prejudiciais ao outro.

Cabe ressaltar que as respostas $H$ e $M$, no Rorschach, são representantes de aspectos associados a dimensões es- táveis da personalidade e que, sem dúvida, concebem o nível do desenvolvimento, as identificações, as qualidades das relações interpessoais e os aspectos mais diferenciados da sociabilidade. Segundo Blatt e Lerner (1983), quanto mais severa a patologia do indivíduo, piores serão suas representações humanas, maior será o grau de dificuldade para manutenção do seu significado na representação do objeto. Desse modo, a ausência de perceptos humanos no protocolo 2 é um indicador de sérios conflitos na conformação da própria identidade, da falta de habilidades empáticas e de um maior comprometimento psicológico, dada a indisponibilidade de recursos para representar /abstrair papéis e funções sociais.

Como últimos indicadores analisados nesse módulo, as frequiências das respostas $S x$ e $F d$ não denotaram diferenciações normativas nos níveis das representações de conotação sexual, bem como indícios de dependência ou imaturidade emocional.

De acordo com os indicadores encontrados no Rorschach, os problemas de ajustamento interpessoal dos participantes, além da falta de autoconhecimento e de referenciais próprios, incidiram nas apreensões fragmentárias e pouco empáticas do outro e das demandas pertinentes às transações sociais humanas, principalmente as que requerem tato, refinamento e sensibilidade, e que se confirmaram ainda nos relatos:

As relações sexuais eram espontâneas, ela vinha me procurar no meu quarto me falando assim: filha é pro senhor e não pros outro... é que faltou juízo das duas partes... Fui incriminado por vingança, confessei sob espancamento e ela não está sofrendo porque não foi presa... Eu só vou sentir arrependimento pelo fato se for eu mesmo o pai da criança, até hoje não sei se o filho é meu.

As pesquisas com pedófilos e homicidas sexuais reclusos, por sua vez, mostraram que são diferentes dos padrões normativos americanos tanto no apego como no desprendimento emocional do outro ( $T \uparrow$ ou $T \downarrow)$ e nos altos níveis de pressões dos instintos $(F M \uparrow)$, sendo que nos primeiros as disposições interpessoais são marcadamente imaturas e fantasiosas $(F d \uparrow ; M p>M a)$; nos os segundos, o pensamento formal moderadamente alterado (WSum6) (Gacono \& Meloy, 1994; Bridges et al., 1998).

\section{Afeto}

É bem comum agressores sexuais sobressaírem-se pelos esforços que empreendem na minimização das suas responsabilidades ou dos danos causados e, particularmente, na condição de reclusão, não surpreenderia que usassem demasiadamente defesas como intelectualização ou indiferença emocional em relação ao ambiente, o que no Rorschach corresponderia, respectivamente, a elevação da variável $2 A B+A r t+A y$ e diminuição do índice $A f r$, não constatadas nos casos estudados. No processamento das emoções, não se mostraram evitativos ( $A f r$ normativo), ambivalentes (Col-ShdBl normativo) ou dispostos ao uso exagerado da intelectualização $(2 A B+A r t+A y$ normativo), 
podendo-se dizer que, naquele período de reclusão, reagiam às suas emoções em níveis similares aos demais (Afr e WSumC normativo), mesmo considerando uma maior propensão a deliberações espontâneas dos participantes 2 e $3(C F \uparrow)$. A hostilidade é outra disposição subjetiva que nem sempre se manifesta nos relatos dos agressores sexuais, embora manifestações hostis e emoções disfóricas sejam referidas nesses indivíduos. Nos casos 1 e 3, os indicadores $S$ e $S$ - não sinalizaram raiva caracterológica e disforia emocional como possíveis forças motivacionais das suas condutas, e no caso 2, as circunstâncias mobilizadoras da raiva não incluem distorções da realidade $(S \uparrow$ e $S$ normativos).

Nos pedófilos, Bridges et al. (1998) encontraram presentes a retração em relação ao meio e a aderência a racionalizações no processamento da raiva. Em virtude do primitivismo afetivo, de mecanismos cognitivos; da falta de empatia e da vulnerabilidade narcísica tais aspectos os aproximam dos achados de Gacono e Meloy (1994) em populações carcerárias portadoras de psicopatia, de transtorno anti-social e das descrições clínicas conduzidas por Groth e Birnbaum (1979). No entanto, no presente estudo estes achados não se confirmaram, com exceção dos importantes déficits relacionais.

\section{Ajustamento Perceptivo e Adequação Cognitiva à Realidade Social}

A medida geral do ajustamento perceptivo explicitou suas capacidades de adequação às convenções da realidade $(X+\%, X-\%$ e $F+$ normativos) e de adaptabilidade aos aspectos socialmente óbvios ( $P$ normativo). A presença de formas peculiares de pensamento (WSum6 não relacionadas às $H$, no caso 1 ), de adesão a impressões idiossincráticas e de orientação dos comportamentos modelados por tais impressões $(X u \uparrow)$ - que a maioria das pessoas não adotaria - não chegam a interferir na percepção dos padrões de conduta vigentes. Pelos indicadores do Rorschach, os três participantes não evidenciaram distorções extremadas ou prejuízos no teste de realidade típicos dos transtornos psicóticos, ao contrário, confirmaram que são capazes de reconhecer as formas convencionais de pensamento e que, possivelmente, façam o uso mais efetivo das convenções sociais mediante as conveniências do momento.

\section{Considerações Finais}

Os resultados obtidos são compatíveis com algumas das características gerais retratadas na literatura internacional sobre agressores sexuais, entretanto, os elementos peculiares a cada um dos participantes impossibilitam enquadrálos em perfis patognomônicos por meio dos indicadores encontrados no Rorschach. A similaridade nos fatores sóciodemográficos, nas condições de reclusão e na aplicação dos procedimentos de pesquisa levam a concluir que as diferenças entre os participantes não se explicam por variabilidade nesses aspectos, mas sim pelo dinamismo próprio de cada um. E o valor do Método de Rorschach como instrumento de avaliação psicológica foi o de gerar dados da personalidade implícitos nos diferentes processos de adaptação à realidade social dessas pessoas, evidenciando as fragilidades das suas organizações psicológicas, o que não necessariamente vai ao encontro das expectativas formuladas no imaginário social.

\section{Referências}

Abel, G. G., \& Rouleau, J-L. (1990). The nature and extent of sexual assault. In W. L. Marshall, D. R. Laws \& H. E. Barbaree (Eds.). Handbook of sexual assault: Issues, theories, and treatment of sex offenders (pp. 257-275). New York: Plenum Press.

American Psychiatric Association. (2002). Manual Diagnóstico e Estatístico de Transtornos Mentais: DSM IV TR (4. ed., C. Dorneles, Trad.). Porto Alegre, RS: Artes Médicas.

Blatt, S. J., \& Lerner, H. (1983). The psychological assessment of object representation. Journal of Personality Assessment, 47, $18-28$.

Código Penal Brasileiro (8. ed.). (2002). São Paulo, SP: Saraiva. Bridges, M. R., Wilson, J. S., \& Gacono, C. B. (1998). A Rorschach Investigation of defensiveness self-perception, interpersonal relationship, and affective states in incarcerated pedophiles. Journal of Personality Assessment, 70(2), 365-385.

Exner, J., Jr. (2003). The Rorschach: A comprehensive system (4th. ed.). New York: John Wiley \& Sons.

Fisher, D. D., \& Beech, A. R. (2004). Adult male sex offenders. In H. Kemshal \& G. McIvor (Eds.), Managing sex offender risk (pp. 25-48). London: Jessica Kingsley.

Gacono, C. B., \& Meloy, J. R. (1994). The Rorschach assessment of aggressive and psychopathic personalities. Hillsdale, NJ: Lawrence Erlbaum.

Groth, A. N., \& Birnbaum, H. J. (1979). Men who rape: The psychology of the offender. New York: Plenum.

Herman, J. L. (1990). Sex offenders: A feminist perspective. In W. L. Marshall, D. R. Laws \& H. E. Barbaree (Eds.), Handbook of sexual assaults: Issues, theories, and treatments of sex offenders (pp. 177-193). New York: Plenum Press.

Kalichman, S. C. (1991). Psychopathology and personality characteristics of criminal sexual offenders as a function of victim age. Archives of Sexual Behavior, 20, 187-197.

Knigth, R. A., \& Prentky, R. A. (1990). Classifying sexual offenders: The development and corroboration of taxonomic models. In W. L. Marshall, D. R. Laws \& H. E. Barbaree (Eds.), Handbook of sexual assault: Issues, theories, and treatment of sex offenders (pp. 23-49). New York: Plenum Press.

Mann, J., Stenning, W., \& Borman, C. (1992). The utility of the MMPI-2 with pedophiles. Sex Offender Treatment: Psychological and Medical Approaches, 6, 59-74.

Marshall, W. L., \& Barbaree, H. E. (1990). An integrated theory of the etiology of sexual offending. In W. L. Marshall, D. R. Laws \& H. E. Barbaree (Eds.), Handbook of sexual assault: Issues, theories, and treatment of sex offenders (pp. 257-275). New York: Plenum Press.

Meloy, J. R., Gacono, C. B., \& Kenney, L. (1994). A Rorschach investigation of sexual homicide. Journal of Personality Assessment, 62(1), 58-67.

Nascimento, R. S. G. F. (2002). Resultados de estudo normativo para o sistema compreensivo do Rorschach: Um estudo para a cidade de São Paulo. Psico-USF, 7, 121-135. 
Pasqualini-Casado, L., Vagostello, L., Villemor-Amaral, A. E. de \& Nascimento, R. G. do (2008).Características da Personalidade de Pais Incestuosos por Meio do Rorschach, Conforme o Sistema Compreensivo.

Organização Mundial da Saúde. (1995). Classificação Estatística Internacional de Doenças e Problemas Relacionados com a Saúde - CID 10 (2. ed.). São Paulo, SP: EDUSP.

Pimentel, S., Schritzmeyer, A. L. P., \& Pandjiarjian, V. (1998) Estupro: Crime ou cortesia? Abordagem sócio-jurídica de gênero. Porto Alegre, RS: Sergio Antonio Fabris.

Shaw, J. A. (1998). Sexual aggression. Washington, DC: Library of Congress.

Sholevar, G. P. (1978). A family therapist looks at the problem of incest. Bulletin of the American Academy of Psychiatry and Law, 11, 75-79.

Sholevar, G. P., \& Schwoeri, L. D. (1998). Sexual aggression within the family. In J. A. Shaw (Ed.), Sexual aggression (pp. 75-101). Washington, DC: Library of Congress.

Willians, L. M., \& Finkelhor, D. (1990). The characteristic of incestuous fathers: A review of recent studies. In W. L. Marshall, D. R. Laws \& H. E. Barbaree (Eds.), Handbook of sexual assault: Issues, theories, and treatment of sex offenders (pp. 231-255). New York: Plenum Press. 